\title{
Concepts of compliance: Understandings and approaches
}

\author{
John F Playle, MSc, BSc(Hons), Dip Counselling, RN, CPN Cert, RNT, Lecturer in Nursing \\ Correspondence: John F Playle, Lecturer in Nursing, School of Nursing Studies, The University of Manchester, Coupland III, \\ Oxford Road, Manchester, M13 9PL, UK. Tel: 01612757954 Fax: 0161275 7566, Email: john.playle@man.ac.uk
}

A paper presented at the inaugural meeting of the Clinical Effectiveness Unit, Faculty of Family Planning and Reproductive Health Care of the Royal College of Obstetricians and Gynaecologists, September 1999.

(Accepted June 30 ${ }^{\text {th }}, 2000$ )

\begin{abstract}
Summary
This paper will take a critical look at the concepts of compliance and non-compliance, both generally and in the specific context of contraceptive use.
\end{abstract}

\section{Key words}

health advice, ideology, compliance, contraception

\section{Introduction}

It needs to be stated at the outset that I view the terms 'compliance' and 'non-compliance' as problematic, expressive of an underlying ideology that assumes there are 'proper' roles for patients to perform which ultimately require a degree of deference to professional expertise. However, the terms 'compliance' and 'non-compliance' are still commonly used in professional literature and discourse. Though there has been a shift towards more 'politically correct' terminology such as 'concordance' and 'adherence', which have a more favourable ring to them and seem less judgmental, they still, I would argue, rest on such an ideology. It was due to a paper that I wrote with a colleague that looked at issues of non-compliance and professional power that I was approached to present today. I was glad to be invited, but had some reticence due to having little background or expertise in the specific areas of sexual health, or contraception. I am grateful to Joan Walsh and Dr David Hicks for their help in contextualising the issues I wish to raise in this more specific area. Some of the issues and questions addressed apply across most areas of health care, having implications for how we conceptualise, practise, and research the ways that patients/clients use health advice, treatments, and professionals. Compliance and non-compliance are of interest to professionals in all areas of health care, and this is reflected in the amount of published literature and research on the subject. A recent search of the Index Medicus revealed over 4000 papers on this subject published within the last 15 years. In the search for more specific literature dealing with compliance and contraception, I had no problem in finding many relevant articles. Most practitioners will recognise non-compliance as a common issue (whether we use this term or not), that often leads to frustration and has personal and social implications for the health and well-being of patients, as well as the effective and efficient use of resources.

My own particular interest in this area developed from a qualitative study into the broader area of patient/client participation in care. ${ }^{1}$ The aim of the initial part of the study was to explore the meanings given to the concept of patient participation, from the perspectives of health care professionals from a range of disciplines. The concept of patient participation in care was defined by professionals as a patient-centred, interpersonal process of 'working together', underpinned by professional beliefs in patients' rights to autonomy, and self-direction. Professionals suggested that this approach differentiated their practice from the paternalism of more traditional approaches.

Although patient autonomy was valued, a 'fine line' demarcated domains of decision making where professionals still believed they knew best. The professional's role was to share information, often suggesting a best course of action. Increased 'co-operation', described as a key outcome of this participative process, was defined primarily in terms of patients making 'appropriate' choices and a willingness to work with the professional - participating in the means and the end. Professionals emphasised notions of patient responsibility (to self primarily), particularly in light of professional's willingness to involve them. The concept of patient participation described by professionals, whilst having an illusion of patient empowerment, appeared to be equally concerned with achieving compliance by means of involving the patient in the process. Such a concept of participation I have defined as 'participative paternalism', where the end is still a form of compliance, though the means appear to be a seemingly more patient-centred approach. In light of this, it can be argued that the concept of patient participation as defined by professionals in this study, and I would argue more generally, whilst being underpinned by ideals of patient autonomy and empowerment, was still to a large extent guided by a desire for compliance. I will come back to explore this ideology later in the paper.

\section{Defining compliance}

The compliance of patients with health care advice and prescribed treatments has increasingly become an area of interest and research. As already highlighted, the literature is replete with studies and papers focussing on compliance. Drug companies' claims for the advantage of their treatments specifically identify 'improved compliance' as a reason for their use over other treatments. ${ }^{2}$ Whilst the term 'non-compliance' is used as a catch-all phrase for behaviour that does not coincide with 'proper' use of advice or treatment, in fact it is far more complex. It covers a multitude of different responses made by patients to advice and prescription, including those who do not comply at all, those who only partially comply, and those who exceed the prescribed therapy/treatment. O'Hanrahan and O'Malley ${ }^{3}$ suggest that the term should only be used where failure to comply is of a nature that appreciably interferes with the goals of treatment. They go on to suggest that failure to achieve the desired therapeutic outcome may be the first 
sign that the patient is not complying with the prescribed treatment or advice. However, such assumptions are oversimplistic and flawed, in that the efficacy of treatments is presumed to be the same for all patients. There are always margins of error, and even in the world of scientific predictability we are, at best, dealing in probabilities.

In terms of the use of contraception, 'non-compliance' as a term may describe a range of behaviours which might include non-use, incorrect use, inconsistent use, and discontinuation whilst still at risk of unintended pregnancy.

Non-compliance then, as a concept, is complex, covering a broad range of potential and actual behaviours or responses to professional advice and prescription. The concern with compliance is not a new one. Hippocrates is reported to have made reference to the fact, that 'patients often lie when they state that they have taken certain medicines'. ${ }^{4}$ Haynes ${ }^{4}$ defines compliance as: 'The extent to which the person's' behaviour (in terms of taking medications, following diets or executing other lifestyle changes) coincides with medical or health advice.' Fletcher 5 puts it in a more simplistic form, suggesting that compliance really means, 'patients doing what the health professionals want them to do'. The term 'coincides' used in the definition offered by Haynes seems less judgmental than the language used by Fletcher which acknowledges the power relationship between health professionals and patients.

Despite the differing terminology used, the issue of power is still central to the definitions; the power to label patient behaviour which does not follow professional prescription as 'non-compliant' still rests with the professional and appeals to a moral and normative dimension involving obligations and responsibilities.

Problems of compliance have been a major factor in developing new forms of medications and treatments, with less complicated regimes, or in long acting forms such as depot preparations administered by professionals, removing the need for the patient to comply on a day-day basis. ${ }^{6}$ Depot injections of phenothiazines, which have no chemical or physiological advantage over consistently taken oral medication, for individuals with mental health problems is one example. In the area of contraceptive methods, the development and use of implants and depot preparations as an alternative to oral contraceptives is another.

In the case of oral contraceptives, the widespread problems of non-compliance have been estimated to account for up to $20 \%$ of unintended pregnancies in the USA, with associated costs of $\$ 2.6$ billion dollars. ${ }^{7}$ In other areas of sexual health advice, non-compliance can have serious health consequences for individuals, as well as current and future partners. The outcomes of noncompliance generally, however, are not always predictable, ranging from no or minimal negative consequences, to severe and, at times, fatal ones. If, as will be noted later, non-compliance is widespread, this also has implications for the assessments of the effectiveness and efficiency of existing and new treatments even in controlled clinical trials, as the general assumption of compliance with trial protocols may be overestimated.

\section{Assessing compliance}

Many studies into compliance have focussed on attempting to assess the nature and frequency of non-compliance. This has proved to be particularly problematic due to issues of poor validity and reliability of measures used, lack of consistency across studies, and the fact that many studies have not used representative samples. ${ }^{8}$ Various methods have been used to assess compliance with treatments, drug treatments in particular. Some of these are technical methods such as checking blood concentration and serum levels of drugs ${ }^{9,10}$ and urine screening for drug metabolites or added markers. ${ }^{11,12}$ Other simpler methods have included pill counts, ${ }^{13}$ checking if prescriptions are dispensed, ${ }^{14}$ and direct questioning of patients. ${ }^{15}$ Other studies have utilised a combination of methods, though Pearson ${ }^{16}$ concludes: "no method of assessing compliance is completely effective'.

Although blood and urine screening offer more objective measures, they are affected by individual variance in metabolic and absorption rates. Pill counts are notoriously unreliable, and direct questioning may have negative effects on the relationship between practitioner and client. Importantly, these methods rarely give any indication of compliance with the regime or schedule of treatment. Studies into contraceptive use are no exception to these problems. ${ }^{17}$ Most studies have used self-reports of contraceptive use. ${ }^{7,17-19}$ A recent study used both selfreport data and electronic dispensing devices to assess consistency of pill taking amongst oral contraceptive users. $^{20}$ The discrepancies between the two measures indicate that many women consistently under-reported missing pills.

A key measure of non-compliance with contraceptive methods might be unintended pregnancy. However, the predictability and incidence of such an outcome is difficult to assess accurately. ${ }^{21}$ Trussel $^{22}$ has challenged the ways in which failure rates of contraception have been calculated, suggesting that this is far more complex than previously thought. Equally, using such an outcome as a measure of compliance does not account for unreported terminations. Other possible signs of poor compliance such as spotting and bleeding may not be recognised and cannot exclusively be linked to inconsistent pill taking, and method discontinuation often goes unreported. ${ }^{23}$

Despite difficulties with accurate assessment, various estimates of the frequency of non-compliance have been made. These are complicated by problems of definition, variation in the groups studied, and differing treatments and methods of assessment. However, reviews of a wide range of studies, have estimated that $25-50 \%$ of patients may at some time be non-compliant with treatment in some way. ${ }^{24-26}$ Studies focusing on consistency of oral contraceptive use also indicate a wide variation in compliance. Overall, across different populations, an aggregation of findings suggests a rate of non-compliance ranging from $16 \%$ to as high as $58 \%$. Almost half of new users of oral contraception discontinue use in the first year, with many still at risk of unintended pregnancy. ${ }^{27-29}$

Evidence also suggests that women discontinuing do not always substitute another method, or adopt a less effective method. ${ }^{30,31}$ Peterson et $\mathrm{al}^{8}$ in their study of oral contraceptive use importantly differentiated between pill only users $(85 \%)$ and dual method users $(15 \%)$. Whilst no statistically significant difference in terms of consistency of pill use was noted amongst these groups, this again raises the problems of an all encompassing definition of compliance and non-compliance. Those women using dual methods who were inconsistent in their use of the pill, whilst being seen as non-compliant with this specific method, are clearly not non-compliant in terms of overall contraceptive use.

Whilst such a broad ranging summary of studies may obscure variations between groups of users, it would appear that non-compliance both generally in health care, and specifically in the area of contraceptive use, is of a scale 
that has clear implications for health care practice. Equally though, if non-compliance is so common, and most studies probably underestimate it's frequency, it can be argued that non-compliance may simply be part of the human condition. It is probably safe to say that in some way, at some time, we are all non-compliant.

\section{Proposed reasons for non-compliance and management strategies}

Many reasons have been proposed for non-compliance, with the majority of research examining links between specific variables. These have included demographic features and other characteristics of the patient population, treatment regimes, diagnoses, type of medication, knowledge, side effects, and satisfaction with the professional-patient relationship..$^{32-35}$ To a large extent, studies into contraceptive use have followed a similar pattern. Many have focused on attempts to identify user characteristics significantly associated with compliant behaviour. These have been based on both retrospective and prospective survey designs, using logistic regression, and multivariate analysis techniques in the search for a noncompliant type. Various factors have been identified as influencing compliance, both generally, and specifically in relation to oral contraceptive use (Table 1).

Table 1 Proposed influences on compliance

\begin{tabular}{ll}
\hline General & Specific to oral contraception (OC) \\
\hline User characteristics & Length of OC use \\
Treatment types and regimes & Daily routine \\
Diagnoses & Relationship status \\
Knowledge/understanding & Ethnicity \\
Side effects & Importance of avoiding pregnancy \\
Patient-practitioner relationship & Partner support for use of method \\
Health beliefs & \\
Type of service provision & \\
\hline
\end{tabular}

The early focus on adolescents seemed to indicate an association between oral contraceptive compliance and age, though it has been suggested that if other factors are taken into account, young women are no more likely to be noncompliant than older women. ${ }^{7}$ Other factors that have been linked to issues of compliance in health care generally and specifically in contraceptive use, are patient information and knowledge, and practitioner-client communication. Both choice and use of contraception are clearly linked to the amount and level of information, understanding and expectations that users have. ${ }^{36}$ Even though choice appears to often be based on the 'least unpleasant of an unpleasant set of alternatives ${ }^{37}$, clearly one would anticipate that knowledge of how to use, potential side effects, and strategies for backup are important pre-requisites for a possibility of compliance. A recent study found that amongst oral contraceptive users, knowledge of when pill efficacy is reduced was good, but knowledge of appropriate actions to take, and obtaining and using emergency contraception was poor. ${ }^{38}$ Other studies have indicated that supplementary written information can lead to an increase in knowledge amongst oral contraceptive users, particularly regarding the window of hormonal safety, and where to obtain emergency contraception. ${ }^{39}$ Whilst there is some evidence to suggest that increased knowledge and understanding may lead to increased compliance, there is a need for more rigorously controlled trials into such links, which are at best tentative at the current time.
Clearly, information links to other factors to do with the practitioner-client relationship as the context within which communication takes place. Rosenberg et $\mathrm{al}^{40}$ found a significant correlation between compliance and satisfaction with the client-provider relationship. Studies in other areas have indicated that patients desire verbal and written information, and that the provision of such information can be related to reduced anxiety, improved recovery, and increased patient satisfaction. ${ }^{41,42}$

The importance of experienced side effects has also been shown to be linked to compliance difficulties although, as discussed earlier, there is the possibility that some of the side effects of oral contraception may in themselves be due to inconsistent use. A number of studies have demonstrated that change in contraceptive method, inconsistent use, and discontinuation can be linked to side effects. ${ }^{27,36,40}$ Some side effects and concerns are predictable and transient and informing clients of this may lead to improvements in use, avoid discontinuation, and increase satisfaction. ${ }^{43}$ Having information can be seen as one form of cognitive control, which aids preparation for events, and leads to the interpretation of events in such a way that perceived threat is lessened. ${ }^{44}$ Information exchange in general, however, also needs to take account of the current expectations, beliefs and understandings of the client as well as being the right type, in the right format and related to the clients' readiness to receive.

Other understandings of non-compliance suggest that client behaviours depend to a large extent on their perception of severity, and susceptibility to, the negative consequences of non-compliance weighed against the perceived benefits if the recommended health action is taken. ${ }^{31}$ However, this often presumes a basis of pure rationality (as judged by professionals). Studies in other areas where potentially life saving treatments are prescribed or recommendations made, and negative and positive outcomes of compliance are perceived, suggest that actual compliance is still problematic. ${ }^{45,46}$

Various strategies to enhance compliance have been developed based on some of the suggested explanations above (Table 2). These range from relatively simple measures such as the provision of dosset boxes, simplification of the treatment regime, and the creation of a regular pill taking habit by association. Recently, more sophisticated approaches to prompt clients to take medications have been developed and used with some success. These have included telephone reminders, patient held alarms, and radio pagers. Other approaches have involved the development of different forms of medication such as long acting or depot preparations, where the need to comply on a day-to-day basis is removed. However, compliance with appointments is still often an issue. Other strategies focussing on enhanced communication and improved information and understanding have demonstrated increased knowledge in some areas and greater satisfaction with the client-provider relationship. However, the links between knowledge, satisfaction, and behaviour are not unequivocally demonstrated, as the relationship between such variables is highly complex. The nature of service provision has also been linked to compliance in terms of accessibility and acceptability. Whilst changes to services may lead to increased access to and satisfaction with services, very few studies have examined the impact on subsequent health behaviours.

The conundrum of compliance is extremely complex, and as yet whilst there are possible indicators as to some possible understandings and explanations, amongst some patients, in some contexts, with some areas of 
Table 2 Strategies to enhance compliance

Simple prompt aids

- dossett boxes, calendar blister packs

More sophisticated reminders

- alarms, telephone, pagers

Simplification of regimes

Altering form of medication

Improved communication/education

Changes in type of service provision

-accessibility, acceptability

treatment/advice, these are still rather theoretical. Despite the wealth of research into determinants and management of compliance, few simple conclusions can be drawn. ${ }^{47,48}$

\section{Ideology and assumptions: Compliance as a moral enterprise}

Having given an overview of some of the issues around current understandings and approaches to compliance in health care, for the remainder of the paper I wish to address some of the ideological assumptions, both implicit and explicit in research, literature and practice. I have already suggested in the introduction to the paper my own view regarding the terms 'compliance' and 'non-compliance', and note that to a degree problems with this term have been acknowledged by others in the specific areas of contraceptive advice and sexual health. ${ }^{49,50}$ An important question to be asked is: why has the issue of compliance, or more precisely, non-compliance, in health care become such a major focus of interest and research? Although there are clearly clinical, economic and academic rationales, other reasons may be linked to ideological assumptions that have dominated the research and literature in this area.

Traditionally, it has been argued that the development and increased availability of 'effective' medications and treatments particularly since the $1950 \mathrm{~s}$, is the main reason for the growing interest in compliance. ${ }^{2,51}$ As these treatments became more widely used, there was greater necessity to ensure appropriate consumption by patients, as well as proper prescription by practitioners. However, such an explanation assumes that sound scientific measures of efficacy are the only foundation of professional beliefs about clinical efficacy. It can be argued that many aspects of professional knowledge are not solely based on science, but are at times also rooted in myth and professional selfbelief. ${ }^{52,53}$ Trostle $^{47}$ contends that most 'healers' in any historical period, whether they be 'professionals' or not, 'tend to believe in and help to reinforce the curative (or preventative) powers of their treatments'.

To a large extent, professional knowledge tends to be founded, justified and legitimised, in terms of what Freidson ${ }^{54}$ calls 'formal knowledge'; accepted as inherently credible because of the status of the producers of that knowledge. Several writers have noted the increasing dominance of health professions in society. ${ }^{55,56}$ The position of professionals as definers of health/illness and 'proper' treatment, has been further legitimised and reinforced through various forms of social and legislative regulation regarding access, and appropriate responses to, advice and treatment. A Foucauldian perspective suggests that many aspects of health care practice, and in particular health promotion and prevention, can be seen as forms of power that exert moral control over individuals. ${ }^{57}$ Increasing concern about compliance may be seen, in part at least, as due to the growing monopoly of professionals and an example of surveillance. Turner ${ }^{58}$ suggests that in contemporary capitalist societies where there is reasonable equity of health care, and where health is seen as a desirable, though limited resource for individuals, there develops an increasing degree of regulation by those in powerful positions. The monitoring of populations, and more specifically in this context, their compliance with treatments and advice, clearly fits within the surveillance framework. This is not to deny the legitimacy of concerns with the use of advice and treatments, or question the beneficent basis of such concerns. However, it is important to examine other, may be less acknowledged or acceptable, moral presuppositions which are often implicit within health practice.

In the same way that much writing on health is really concerned with illness, so the literature and research on compliance is primarily concerned with non-compliance. Compliance with health advice and treatment is largely seen as an unproblematic rational response to morally neutral advice and prescription based on professional beliefs about benefits for clients. Again, this is not to deny that benefits are real or that consequences of non-compliance are irrelevant - to do this would be to deny the main rationales and intentions underpinning most health professional practice. However, it must be acknowledged that 'compliance can be understood as a response to a particular expression of power or set of normative expectations' ${ }^{59}$ The nature of social regulation expressed in the ideology of compliance is far more complex and subtle than the direct, explicit imposition of professional views based on formal authority, which typified earlier sociological analyses of professional power. Social regulation is equally achieved through more subtle processes of health education, promotion and advice that appeal to 'rational' thought, and clients acting in their own best interest. Through this process, individuals are encouraged to become selfregulating and incorporate a duty to be well into their everyday repertoires'. ${ }^{60}$ This, combined with the notion that the pursuit of health is a key aspect and expression of social membership and good citizenship, suggests that whilst compliance may be beneficial, it is not neutral. It rests upon a moral foundation of obligation and responsibility to self, others, and society. ${ }^{61}$ The very notion of compliance implicitly requires, to some degree, a dependent layperson and a dominant professional; one giving 'expert' advice, suggestions, and prescription, and the other carrying them out.

At one level, the literature and research on compliance appears to be about improving health care. At a covert level it can be argued that it is also about issues of professional power and control, and represents an ideology based on professional beliefs concerning the 'proper' roles of patients and professionals. Non-compliance can be seen as a label that denies the legitimacy of various actions and behaviours that differ from professional prescription, advice and expectations.

\section{Assumptions of deviancy}

Implicit in the dominant professional world view, as seen in the literature, is an assumption and belief that the role of the professional is to diagnose, prescribe and treat. The reciprocal role of the patient is to comply with such 'expert' diagnosis and treatment. Non-compliance thus challenges such professionally held beliefs, expectations and norms. This has led to a labelling of such behaviour as deviant, and an inherent tendency to view such patients as both deviant and culpable. Further, this emphasises the principle of beneficence invoked by the paternalistic professional rather than promoting the autonomy of the patient. Stimson ${ }^{62}$ 
argues that the underlying perspective of early research into non-compliance, generated 'a search for a cause that must in a sense inevitably be seen as residing in the patient'.

To a large extent, this perspective has not changed, though it has become obfuscated by different language and terminology. Common terms used to refer to behaviour which does not comply, include: 'default', 'non-adherence', 'failure', 'refusal', 'resistance' and 'non-co-operation'. Patients displaying such behaviours are classified as noncompliers or defaulters. Fawcett ${ }^{63}$ describes the way in which the terminology used for such behaviour has changed from that of 'non-compliance' to a preference for the term 'nonadherence'. Despite the seemingly less judgmental nature of this term, it still carries with it some of the implicit assumptions which lead to the negative labelling of such behaviours and in turn patients themselves as 'difficult' or troublesome. In essence, such behaviour is seen as 'irrational' and 'deviant', with patients being labelled as 'problem patients'. ${ }^{62}$ Such patients are often viewed as hindering the 'normal' process and practice of health care, often leaving the professional feeling exasperated and concerned with the effective outcomes of treatment and advice. ${ }^{64}$

Although the literature and research emphasises a relationship of equality, it rarely allows for patients to disagree or reject professional advice. Even more, patientcentred approaches that emphasises factors external to the patient as leading to compliance problems such as the inaccessibility or inappropriateness of services, still presume that if barriers are removed, compliance will be the acceptable outcome. The theme of co-operation as an outcome of patient participation in my own study seemed to suggest that compliance with professional advice was still the ultimate expectation. Patients were not only expected to co-operate in the ends, but also in the means, by taking a more pro-active role that demonstrated a willingness to participate. What was espoused as a 'right' to participate was clearly transformed into a moral imperative and duty to take an active role - given patient ability and creation of the right climate. By showing a willingness to participate sharing and seeking information and desiring appropriate involvement in decision making - the professional ideal of patient-centred care was rewarded. Patients willing to participate were judged as being motivated and accepting responsibility for their health. Such a belief in, and expectation of participation as a duty, challenges the autonomy and right to self-determination, which was described by professionals as the very basis of participation itself. Patients who choose not to participate in the process, and also choose not to co-operate in the outcome (complying with professional advice), may be doubly judged as neither 'motivated' nor 'responsible'.

\section{Control of deviancy: Benevolent coercion.}

Efforts to control compliance have included technical measures, such as the manipulation of the regimen or in some cases changing the form of medication. ${ }^{65}$ The development of forms of long acting medications such as depot drugs, and their increased use, may also be seen as linked to the issue of compliance. The patient is viewed as irresponsible or unreliable for various reasons, and therefore the professional controls the administration of the drug. Attempts to increase compliance by education, along with the emphasis on 'clear' communication, implicitly view the patient as ignorant and forgetful. Rather than attempting to help the patient to reach 'informed consent', these methods can be seen as attempts to neutralise patient beliefs or actions, that run contrary to professional views.
The literature is primarily concerned with teaching professionals how to 'manipulate' patient behaviour, disguised as a more 'human' approach to relationships Scheid-Cooke ${ }^{66}$ terms such measures as 'benevolent coercion'. The tendency throughout the literature is to promote beneficent interventions by the professional based on a more subtle, yet still paternalistic, framework.

Many writers and researchers have focused on the professionals' communication to the patient, rather than communication between the two, and suggest the use of information giving as a method of correcting misinformation. This is clearly evident in the literature on contraception, where it is suggested that misinformation or misinterpretation of side effects needs correcting to increase compliance. Whilst side effects may be transitory, medically insignificant, or only 'perceived' by clients, to simply try to correct the clients' view without seeking to understand from their perspective, is to resort to a form of persuasion based upon an expectation of deference to professional expertise. Perceived side effects are real for clients, even if not fitting into a scientific, evidence based framework of rationalism. A lack of statistical significance or correlation does not negate the personal significance and association for the client. Personal significance may be far more influential on compliance than evidence based counter arguments. The literature on managing compliance also suggests that professionals need to communicate treatment regimes and advice with clarity, brevity and emphasis, as patients do not tend to ask questions. Because of this, the patient '.......deprives the clinician of the feedback for improved communication'. ${ }^{67}$ However, Tuckett ${ }^{34}$ found in his study that when patients did offer views or ideas, the majority of doctors in the sample either made no effort to encourage elaboration, or actively interrupted these expressions. Calnan ${ }^{68}$ effectively summarises the situation when he states that: 'Non-compliance has been viewed in various ways, but common to all of them is the portrayal of the non-compliant patient as deviant or having deviant attributes'.

\section{Assumptions of patient passivity}

So far I have argued that within much of the literature regarding non-compliance there is an inherent tendency to view patients who do not comply as deviant. There is also often an assumption that patients are passive recipients of treatment. The focus on professional-patient interactions in many studies has assumed that professionals are the major source of beliefs regarding health, and behaviours related to health. Behaviour related to health has been viewed in terms of the 'proper' use of professionals and the treatments they offer. However, various researchers have found that the influences on health beliefs and health behaviour are much wider than this. ${ }^{69}$ They have shown that patients actively evaluate treatments and advice in light of beliefs about treatments, the nature of health, measures that improve health and the use of professional advice and prescription. Individuals are often in the 'patient role' for only a minute fraction of their lives, yet the influence of these passing brief encounters with the professional world, is presumed to be of prime importance. The research from a professional perspective could reach no other conclusion. It has rarely followed the individual from the professional setting into their wider world.

The identification of a 'lay referral system' indicates that individuals engage in a complex process before consulting health professionals. This involves assessment of their own health needs, use of significant others, and the use of various other measures to increase health. The individual 
may then seek professional help, having already made judgements about their own needs, treatment, and expectations of professionals. There is certainly evidence to suggest that this is the case with choice and use of contraceptive methods and advice. ${ }^{36}$ This complex process suggests that patients actively evaluate professional treatments and advice - an alternative view to the myth of patient passivity.

The perspective of many studies has failed to consider patients as evaluative and critical in their use of professional advice and prescription. Based on a positivist epistemology, they have often focused on studying 'objective' external variables that may account for noncompliance. On the basis of correlations, at times contradictory, causative links have been inferred and methods of control suggested. However, bearing in mind that the survey methodologies adopted are in themselves problematic, to move from statistical inference to causal effect in an area of such complexity blurs the boundaries between the factual and actual. Many factors of statistical significance bear little relation to the complex world of human perception, understanding and behaviour.

Whilst such studies may be useful in terms of identifying markers for more complex psychosocial influences, and the starting point for greater exploration, within a surveillance framework they may be seen as attempts to identify a noncompliant 'type'. The gendered nature of much of the literature on contraceptive use that still assumes that contraception is a female responsibility requires further critique where compliance and non-compliance may be seen as expressions of moral relations between women and others. Even studies into contraceptive use amongst men have tried to categorise them into different types and is saturated in the language of responsibility - the 'opportunistic user', the 'passive user' and the motivated and responsible 'prepared user'. ${ }^{70}$ Such studies have often been based on expectations of professionals, and focused on whether patients have complied with advice and treatment, rarely asking what they may have done instead.

They have failed to consider, or have thought of as irrelevant, the ways in which individuals give meaning and definition to their own behaviour, based on beliefs, expectations and constructs. Little attention has been paid to what the process of professional prescription and advice means to patients, as well as their ideas about the use of such advice and treatments. Such a view of patients as passive recipients of health care is based on a belief in the legitimacy of professionals as 'experts'. It has its basis in professional self-belief systems as much as in beliefs about the efficacy of treatments prescribed. In what Becker ${ }^{71}$ terms a 'hierarchy of credibility', patients are clearly at the bottom. As Stimson ${ }^{62}$ points out, '...default is by implication irrational in the light of medical (professional) rationality'.

\section{Conclusion}

Within this paper it has been suggested that whilst the increase in concern with compliance is understandable from the perspectives of clinical effectiveness and economic efficiency, it can also be viewed in terms of professional power and control within a surveillance framework. The concept of compliance presented throughout most of the literature and research can be seen as an ideology based on professional beliefs about the 'appropriate' behaviour of patients, viewing non-compliance as deviant and irrational, and assumptions that on the whole patients are passive recipients of advice and treatment. Such an ideology has been the basis of various research strategies and potentially coercive interventions, that whilst appearing clinically appropriate, serve to justify and reinforce professional authority and power. Even those views and approaches based within more neo-liberalist frameworks of client empowerment and client self interest are still based on notions of moral obligation and responsibility. Geiger ${ }^{72}$ cynically proposes that client participation and empowerment are often part of a rhetoric where professionals decide the ends, with patients participating in the means.

Obviously, the issue of compliance is a necessary area of interest, and I am not arguing that efforts to improve compliance should be abandoned. However, the current ideology of compliance outlined above is inappropriate. An alternative approach must question the beliefs and assumptions that have been the implicit basis of most research and literature. A re-conceptualisation of the professional-patient role is called for. Patients need to be viewed as active participants rather than passive recipient in their own health care. There is a need to see patients as individuals who construct and give meaning to their encounters with professionals, and actively evaluate treatments prescribed and advice given. The starting point for further examination and understanding of compliance must be an acknowledgement of the moral and normative basis of the current conceptualisation.

Research needs to be informed by an alternative epistemology, which gives credence to the meanings given to the world by individuals - the 'inner perspective'. More qualitative research is needed that focuses on exploration and understanding of the use of professional treatment/advice, not in order to control, but as a basis for a more negotiated use of professional-patient relationships. Such research, though different from the traditional quantitative approaches, still demands rigour and reasonable sample size and selection. Non-compliance is highly complex and must be seen as multi-dimensional.

The use of non-compliance as a negative label that denies the legitimacy of behaviours that differ from professional prescription is unacceptable. Such a label is based on, and reinforces the view of the professional as dominant, the patient as passive, and non-compliance as deviancy. It distances the professional from the patients' actions, judging rather than analysing and understanding.

In terms of practice, an acknowledgement of the 'normality' of non-compliance (for whatever reasons) within a permissive climate, may aid the creation of the basis for a more open dialogue between professionals and patients.

\footnotetext{
References
1 Playle JF. Working Together: Collaboration and Control. An analysis of the concept of patient particpation in Health Care. Unpublished MSc Thesis. University of Huddersfield. 1997. Kleinman DL, Cohen LJ . The decontextualisation of Mental illness: The portrayal of work in psychiatric drug advertisements. Social Science and Medicine 1991; 32(8): 867-874. O'Hanrahan M, O'Malley K. Compliance with drug treatment. British Medical Journal 1981; 283: 298-300.

Haynes RB. Introduction In: Haynes R B , Sackett DL, Taylor DW [eds] Compliance in Health Care. Baltimore: John Hopkins Press. Baltimore, 1979.

Fletcher RH. Patient compliance with therapeutic advice: A modern view. Mount Sinai Journal

of Medicine 1989; 56(6): $453-458$.
Johnson DAW. The long acting depot neuroleptics. In: Granville-Grossman K (ed) Recen advances in clinical Psychiatry No 4. London: Churchill-Livingstone, 1982. Rosenberg M, Waugh MS, Long S. Unintended pregnancies and, misuse and discontinuation of oral contraceptives. Journal of Reproductive Medicine 1995; 40: 355-360. Peterson LS, Oakley D, Potter LS, et al. Women's efforts to prevent pregnancy: consistency of oral contraceptive use. Family Planning Perspectives 1998; 30(1): 19-23. Jack DB. Evaluation of a simple method to check compliance with anti-hypertensive drug therapy Clinical Pharmacology Therapeutics 1980; 18: Pt 1: 606-612.

Oakley D, Sereika S, Bogue EL. Oral contraceptive pill use after an initial visit to a family planning clinic. Family Planning Perspectives 1991; 23: 150-154

Ballinger BR, Simpson E, Stewart MJ. An evaluation of a drug administration system in psychiatric hospital British Journal of Psychiatry 1974; 125: 202-207.

Jay MS, DuRant RH, Litt IF. Effect of peer counsellors on adolescent compliance in use of oral contraceptives. Pediatrics 1984; 73 (2): 126- 131

DuRant R, Jay M, Schoffit T, Litt I. Influence of psychosocial factors on adolescen compliance with oral contraceptives. Journal of Adolescent Health Care 1984; 5(1): 1-6.

Rashid A. Do patients cash prescriptions? British Medical Journal 1982; 284: 24-26.

15 Diehl AK, Sugarek NJ,Bauer RL. Medication compliance in non-insulin dependent diabetes: a randomised comparison of chlorpropamide and insulin. Diabetes Care 1985; 8(3): 219- 223.
} 
16 Pearson RM. Who is taking their tablets British Medical Journal 1982; 285 (6344): 757-758. Oakley DY, Yu MY, Zhang YM, et al. Combining qualitative with quantitative approaches to study contraceptive pill use. Journal of Womens Health 1999; 8(2): $249-257$.

18 Emans SJ, Grace F, Woods E, et al. Adolescents' compliance with the use of oral contraceptives. Journal of American Medical Association 1987; 257: 3377-381.

Rallassone ML. Risk of contraceptive discontinuation among adolescents Journal of

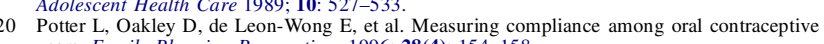

Rosenberg M, Waugh MS. Causes and consequences of oral contraceptive non-compliance.

Trussell J. Contraceptive efficacy in Hatcher RA, Trussell J, Stewart F, et al. Contraceptive Technology $\left(17^{\text {th }}\right.$ ed). New York: Ardent Media, 1998.

Grady WR, Hayward MD, Florey FA. Contraceptive discontinuation among married women in the United States. Studies in Family Planning 1988; 19: 227- 235.

Sackett DL, Snow JC. The magnitude of compliance and non-compliance. In: Haynes RB, Evans L, Spelman M. The problem of non-compliance with drug therapy. Drugs 1983; 25: $63-76$.

26 Heszen-Klemens I. Patients' compliance and how doctors manage this. Social Science and Medicine 1987; 24(5): 409-416.

Trussell J, Hatcher RA, Cates W, et al. Contraceptive failure in the United States: A critical review of the literature. Studies in Family Planning 1987; 18: 237 -283.

Hatcher RA, Stewart F, Trussel J et al (eds) Contraceptive Technology 1990 - 1992. New York:

Ortho Pharmaceutical Corporation. Report on the 1992 Ortho Annual Birth Control Survey. New Jersey: Raritan, 1993.

Pratt WF, Bachrach CC. What do women use when they stop using the pill. Family Planning

Perspectives 1987; 19: $257-266$.
Trussell J, Kost K. Contraceptive failure in the United States: an update. Studies in Family DiMatteo M, DiNicola D. Social Science and the Art of medicine: From Hippocrates to Holism. In: Friedmann H \& DiMatteo M (Eds). Interpersonal issues in Health Care. New York: Academic Press, 1982.

33 Ley P. Patients understanding and recall. In: Pendleton D, Hasler J. Doctor-Patient

34 Tuckett D. Meetings between Experts. London: Tavistock, 1985.

Waller D, Altschuler K. Perspectives on patient non-compliance. Hospital and Community

36 Walsh J, Lythgoe H, Peckham S. Contraceptive choices: supporting effective use of methods.

Ahoices in family planning. London: Family Planning Association, Little

Little P, Glew C, Kelly J, et al. Contraceptive knowledge: development of a valid measure and survey of
$98-100$.

39 Smith LF, Whitfield MJ. Women's knowledge of taking oral contraceptive pills correctly and of emergency contraception: effect of providing information leaflets in general practice. British Journal of General Practice. 1995; 45(397); 409-414.

40 Rosenberg MJ, Waugh MS, Burnhil MS. Compliance, counselling and satisfaction with oral contraceptives: A prospective evaluation. Family Planning Perspectives 1998; 30(2); 89-92 and 104 .

41 Wilson-Barnett J, Oborne J. Studies evaluating patient-teaching: implications for practice. International Journal of Nursing Studies 1983; 20: 33-44.

42 Hames A, Sterling E. Choice aids recovery. Nursing Times 1987; 83(8): 49-5

Belsey EM. The association between vaginal bleeding patterns and reasons for discontinuation of contraceptive use. Contraception 1988; 38: 207-225
44 Lazarus RS, Folkman S. Stress, Appraisal and Coping. New York: Springer, 1984

45 Griffiths S. A review of factors associated with patient adherence and the taking of prescribed medicines. British Journal of General Practice 1990; 40: 114 - 116.

46 Singh N, Squier C, Sivek C, et al. Determinants of adherence with antiretroviral therapy in patients with human immunodeficiency virus: prospective assessment with implications for enhancing adherence. AIDS Care 1996; 8(3): 261-269.

7 Trostle J. Medical compliance as an ideology. Social Science and Medicine 1988; 27(12): $1299-1308$

48 Playle JF, Keeley P. Non-compliance and professional power. Journal of Advanced Nursing

49 Belfield T. Problems of compliance in contraception. British Journal of Sexual Medicine 1992; May/June: 76-78.

50 Baraitser P. Power and knowledge in family planning consultations: can a re-analysis of Boctorpant interacion improve client fatis action. British Journal of Family Planning 1995 ; 21: 18-19

51 Steingard S, Allen M, Schooler R. A study of the pharmacologic treatment of medication compliant schizophrenics who relapse. Journal of Clinical Psychiatry 1994: 55(11):470-472. Posner T. Magical elements in orthodox medicine. In: Dingwall R [Ed] Healthcare and healthcare knowledge. London: Croom-Helm, 1977.

Sackett DL, Haynes RB, Guyatt GH, et al. Clinical epidemiology: A basic science for clinical medicine. Boston: Littlebrown \& Co, 1991.

54 Freidson E. Professional powers: a study of the institutionalisation of Formal knowledge. Chicago: University of Chicago Press, 1986.

55 Foucault M. Madness and civilisation: a history of insanity in the age of reason. New York: Pantheon, 1965

56 Habermas J. New Social Movements Telos 1981; 57: 194-205.

57 Turner BS. Foreward: from governmentality to risk: some reflections on Foucault's contribution to medical sociology. In Petersen A, Burrows R (eds) Foucault, Health and Medicine. London: Routledge, 1997.

58 Turner BS. The body and society: Explorations in social theory. London: Sage, 1987.

59 Howson A. Cervical screening, compliance and moral obligation Sociology of Health \& Illness 1999; 21(4): 401- 425 .

60 Howson A. 1999, ibid.

61 Rose N. Governing the Soul: the shaping of the private self. London: Routledge, 1990

62 Stimson G. Obeying Doctors Orders - A view from the other side. Social Science and Medicin 1974; 8: 97-105.

63 Fawcett J. Compliance: definitions and key issues. Journal of Clinical Psychiatry 1995; 56 (Suppl. 1): 4-8.

64 Moore KN. Compliance or collaboration? The meaning for the patient. Nursing Ethics 1995; 2(1): 71-77.

Cramer JA. Optimizing long-term patient compliance. Neurology. 1995; 45(2, Suppl.1):

66 Scheid-Cooke TL. Controllers and controlled: an analysis of participant constructions of outpatient commitment. Sociology of Health and Illness 1993; 15(2): 179-198.

Ley P. Satisfaction, compliance and communication. British Journal of Clinical Psychology. 1982; 21: 241-254

60 Calnan M. Health and Illness: The Lay Perspective. London: Tavistock, 1987. Science an

70 Medicine 1985; 20(1): $29-37$. opportunities for clients. Sexual health, contraception and men - a training resource. London: Health Education Authority, 1998.

71 Becker H. Whose side are we on. In: Filstead WJ (ed) Qualitative methodology. Chicago:

72 Geiger H. Community control - or community conflict? National Tubercular Respiratory Disease Association Bulletin 1969:55(11): 4-11. 